\title{
SYSTEMIC AND LOCAL EFFECTS OF THE APPLICATION OF A TOURNIQUET
}

\author{
L. KLENERMAN, MEENAKSHI BISWAS, G. H. HULANDS, A. M. RHODES
}

From Northwick Park Hospital and Clinical Research Centre

\begin{abstract}
The effect of the application of a tourniquet to a limb and the release of the accumulated metabolites have been investigated with reference to the acid-base level in the blood from the limb and in the right atrium. Investigations have been carried out experimentally in rhesus monkeys and observations have been made on patients undergoing reconstructive operations on the knee. The acidotic blood from the ischaemic limb produces little systemic effect. The limb recovers in approximately $\mathbf{4 0}$ minutes after a tourniquet has been in place for four hours. Three hours is recommended as a reasonable upper limit for the safe application of a pneumatic tourniquet.
\end{abstract}

Although a pneumatic tourniquet is used daily in orthopaedic surgery, the length of time it is kept in place varies according to local practice. There have been few reports describing the systemic effects on the ischaemic limb (Déry et al. 1965; Solonen et al. 1968). Complete arrest of the circulation to the limb produces acidosis and changes in levels of potassium (Stock, Bohn and Isselhard 1971; Wilgis 1971), which in theory could result in effects on the rhythm of the heart when the tourniquet is released. Although changes in the acidbase status of the blood leaving the limb have been described, the state of the blood reaching the heart after the release of a tourniquet has received little attention (Modig, Kolstad and Wigren 1978). This animal and clinical study was undertaken to establish whether any biochemical changes in the limb are reflected in the right atrium. In addition, the time taken for the ischaemic limb to recover was investigated.

\section{MATERIALS AND METHODS}

Animal studies. Adult rhesus monkeys weighing from 3.5 to 5.0 kilograms were used. After an intramuscular injection of ketamine hydrochloride, 10 milligrams per kilogram, anaesthesia was induced with nitrous oxide, oxygen and halothane. Anaesthesia was maintained with 33 per cent oxygen in nitrous oxide and 0.6 to 0.7 per cent halothane. Ventilation was controlled using a Harvard rodent ventilator which was adjusted to produce an arterial $\mathrm{PCO}_{2}$ of 4.8 to 5.5 kilopascals. An intravenous infusion of 0.18 per cent saline with 4.2 per cent dextrose was used for fluid replacement throughout the experiment. The right internal carotid artery was cannulated and connected to a Bell and Howell pressure transducer for continuous monitoring of the blood pressure on a Devices M19 light channel recorder. The right atrium was catheterised through the internal jugular vein. In a preliminary series of experiments the position of the cannula in the right atrium was verified radiographically. However, it was found that an accurate placing of the cannula was possible by external measurement alone and in the latter part of the study the use of radiographs was discontinued. A second cannula was passed

retrograde into the femoral vein of the limb to which the tourniquet was to be applied. An Esmarch's bandage to exsanguinate the limb was used for the initial experiments but its use was later discontinued as it was considered likely to interfere with the patency of the cannula in the limb. An infant-sized Kidde tourniquet cuff five centimetres wide was applied to the experimental limb and inflated to a pressure of 300 millimetres of mercury for a predetermined time from one to five hours. At regular intervals during the period when the tourniquet was in place samples were taken over a period of one minute from the cannula in the right atrium to establish control values for acid-base status and for potassium. After the release of the tourniquet further samples were taken simultaneously from both the internal jugular route and the femoral vein for periods as long as two hours.

Whenever possible all samples were immediately measured for $\mathrm{PCO}_{2}, \mathrm{pH}$, excess of base and standard bicarbonate. If this was not possible samples were stored in ice for not longer than 30 minutes. An automatic IL 613 gas analyser was used for all the acid-base measurements and any necessary temperature corrections applied. A Corning 450 flame photometer was used for the potassium measurements. Any haemolysed specimens were discarded.

Clinical studies. Patients who were about to undergo total knee replacement or a high tibial osteotomy for rheumatoid arthritis or osteoarthritis were informed of the studies and consented to participate. All patients received an appropriate premedication of papaveretum and atropine. Anaesthesia was induced with thiopentone, an intravenous injection of pancuronium was given and intubation was carried out. Anaesthesia was maintained with nitrous oxide, oxygen and phenoperidine, and occasionally halothane (less than 0.5 per cent). Ventilation was adjusted for a standard $\mathrm{Pa}, \mathrm{CO}_{2}$ of 5.4 kilopascals. A cannula was passed via the right internal jugular vein into the atrium and its position checked by looking for atrial oscillations; five per cent dextrose solution was infused. An intravenous drip of Hartmann's solution was set up in one forearm. The electrocardiogram was continuously displayed and the temperature monitored by a nasopharyngeal probe. An Esmarch's bandage was used to exsanguinate the site of operation and a 10-centimetre Kidde tourniquet cuff inflated to occlude the arterial flow at a pressure of twice the pre-induction systolic pressure. During the operation several samples were taken from the internal jugular cannula to establish baseline values for blood analysis from the central venous pool. At the end of the operation pressure dressings were applied to

L. Klenerman, ChM, FRCS, Consultant Orthopaedic Surgeon $M$. Biswas, FFARCS, DA, Senior Registrar in Anaesthesia G. H. Hulands, FFARCS, Consultant Anaesthetist Mrs A. M. Rhodes, BSc, MIBiol, Technician in the Division of Anaesthesia

Requests for reprints should be sent to Mr L. Klenerman.
Northwick Park Hospital and Clinical Research Centre, Watford Road, Harrow, Middlesex HA1 3UJ, England. 
the limb with the tourniquet still inflated. Samples of blood were taken from the atrium via the internal jugular cannula, and also from the femoral vein of the operated limb by direct needle stab just before releasing the tourniquet. When the tourniquet was released samples were taken simultaneously from the femoral needle and the internal jugular cannula for a period of approximately 15 minutes, and then intermittently from the jugular cannula for approximately two hours. These samples were analysed as described above.
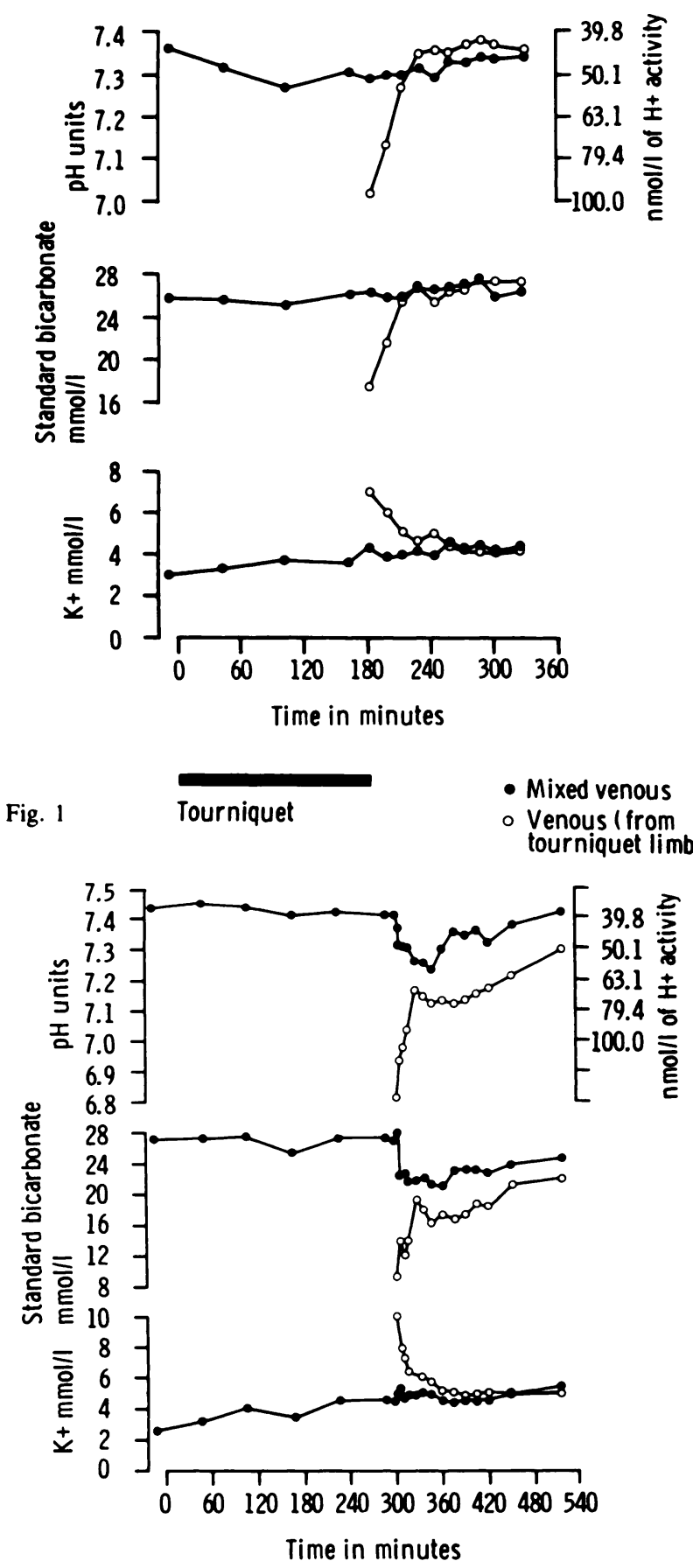

Fig. 2

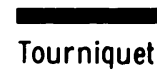

- Mixed venous

- Venous (from tourniquet limb)

Typical patterns of response to the application of a tourniquet to the thigh of a rhesus monkey. Figure 1 -Tourniquet applied for three hours. Figure 2-Tourniquet applied for five hours.
There were nine patients (three men and six women). The average age was 68 years (range 51 to 80 years). The tourniquet was inflated for periods ranging from 70 to 186 minutes.

\section{RESULTS}

Animal experiments. When the tourniquet was released samples taken from the right side of the heart showed little or no change in acid-base status (Figs 1,2 and Table I). The longer the tourniquet had been in place the greater were the biochemical changes in the limb (Fig. 3). The readings for $\mathrm{pH}$, potassium and $\mathrm{PCO}_{2}$ in the right atrium immediately before the release of the tourniquet were taken as 100 per cent. Then each subsequent reading taken from the atrium and the femoral vein was expressed as a percentage of the initial reading. The

Table I. Analysis of blood samples before and after the release of the tourniquet

\begin{tabular}{|c|c|c|c|c|}
\hline & \multicolumn{2}{|c|}{ Venous* } & \multicolumn{2}{|c|}{ Mixed venous $\dagger$} \\
\hline & Mean change $\ddagger$ & SD & Mean change & SD \\
\hline PATIENTS $(n=9)$ & & & & \\
\hline $\mathrm{K}^{+} \mathrm{mmol} / \mathrm{l}$ & 1.80 & 1.05 & 0.5 & 0.2 \\
\hline $\begin{array}{l}\text { Standard } \\
\text { bicarbonate } \\
\mathrm{mmol} / \mathrm{l}\end{array}$ & 3.8 & 1.3 & 2.5 & 0.9 \\
\hline $\begin{array}{l}\mathrm{nmol} / \mathrm{l} \text { of } \\
\mathrm{H}^{+} \text {activity }\end{array}$ & 16.6 & 12.8 & 4.9 & 2.0 \\
\hline MONKEYS & & & & \\
\hline $1-3$ hours $(n=7)$ & & & & \\
\hline $\mathrm{K}^{+} \mathrm{mmol} / \mathrm{l}$ & 2.5 & 0.9 & 0.4 & 0.3 \\
\hline $\begin{array}{l}\text { Standard } \\
\text { bicarbonate } \\
\mathrm{mmol} / \mathrm{l}\end{array}$ & 6.4 & 1.7 & 1.9 & 1.7 \\
\hline $\begin{array}{l}\mathrm{nmol} / \mathrm{l} \text { of } \\
\mathrm{H}^{+} \text {activity }\end{array}$ & 33.9 & 13.1 & 5.4 & 3.8 \\
\hline 4 hours $(n=2)$ & & & & \\
\hline $\mathrm{K}^{+} \mathrm{mmol} / \mathrm{l}$ & 3.9 & & 0.5 & \\
\hline $\begin{array}{l}\text { Standard } \\
\text { bicarbonate } \\
\text { mmol/l }\end{array}$ & 8.8 & & 2.9 & \\
\hline $\begin{array}{l}\mathrm{nmol} / \mathrm{l} \text { of } \\
\mathrm{H}^{+} \text {activity }\end{array}$ & 52 & & 5.3 & \\
\hline 5 hours $(n=2)$ & & & & \\
\hline $\mathrm{K}^{+} \mathrm{mmol} / \mathrm{l}$ & 4.45 & & 0.28 & \\
\hline $\begin{array}{l}\text { Standard } \\
\text { bicarbonate } \\
\mathrm{mmol} / \mathrm{l}\end{array}$ & 14.2 & & 2.9 & \\
\hline $\begin{array}{l}\mathrm{nmol} / \mathrm{l} \text { of } \\
\mathrm{H}^{+} \text {activity }\end{array}$ & 89 & & 5 & \\
\hline
\end{tabular}

*Venous blood from the limb to which the tourniquet had been applied

t Mixed venous blood of the right atrium

$¥$ Mean change is the difference between the level of a control reading from blood from the right atrium taken before the release of the tourniquet and the reading showing the greatest change after release of the tourniquet 


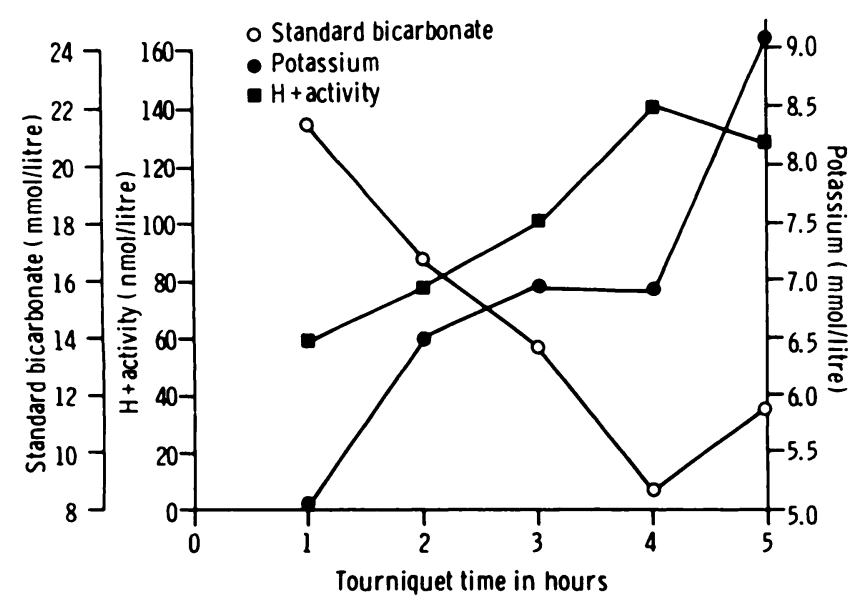

Fig. 3

The mean of the initial readings of the variables studied taken in the first sample of blood from the limb after the release of the tourniquet plotted against the time during which the tourniquet was inflated.

results obtained were plotted on semilogarithmic paper. The "best fit" line for each variable was drawn for the samples from the heart and limb. Recovery time for the limb was measured at the point where the initial slope of the curve for the limb intersected with the line for readings from the right side of the heart. This was plotted against the time the tourniquet had been inflated (Fig. 4). After one hour with the tourniquet, recovery occurred in the limb within 20 minutes. For tourniquet periods of two to four hours, recovery of all variables was complete with 40 minutes. However, after five hours, recovery for potassium and standard bicarbonate
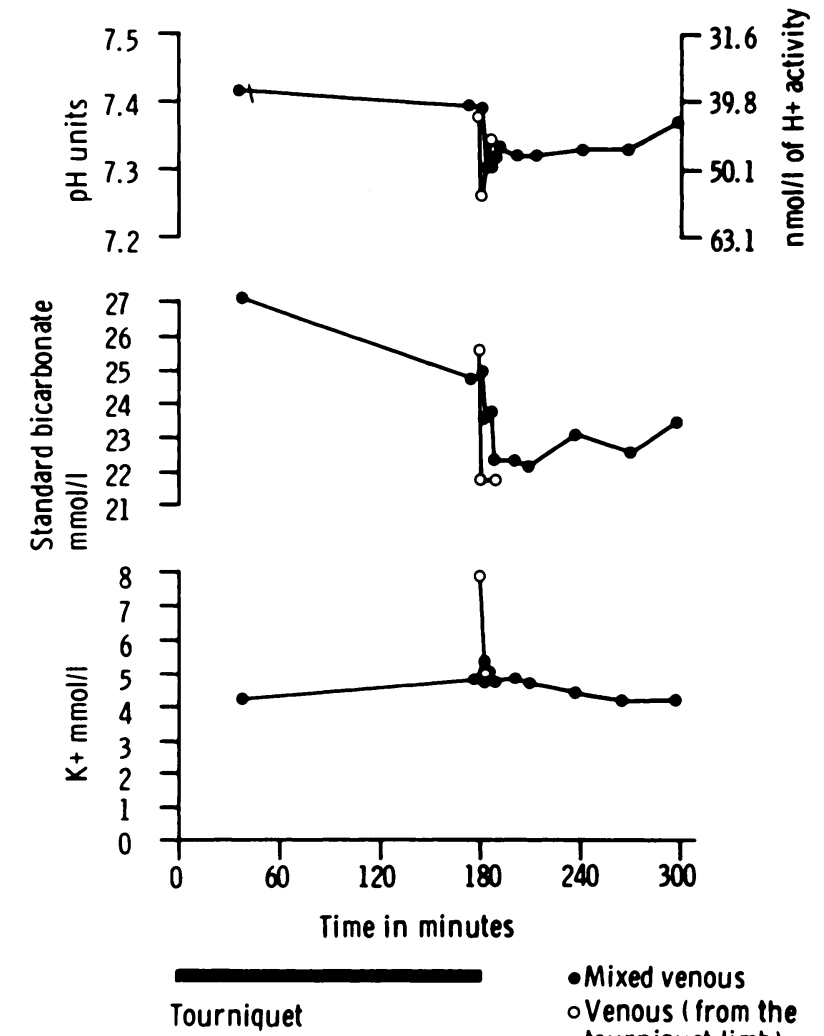

- Mixed venous oVenous ( from the tourniquet limb)

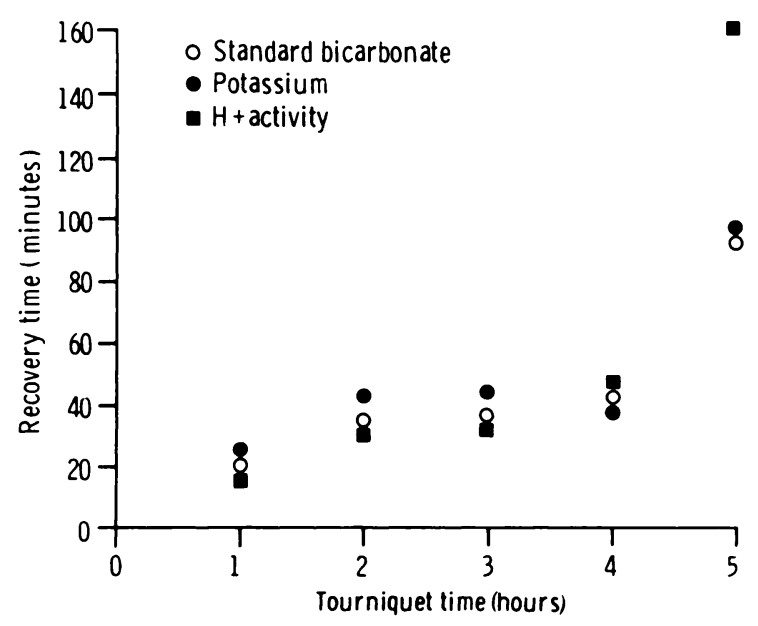

Fig. 4

The estimated recovery time for each variable in the blood supply in the limb subjected to ischaemia in relation to the time the tourniquet was used.

occurred in 1 hour 40 minutes but $\mathrm{pH}$ returned to the level of the blood in the right atrium only after 2 hours 40 minutes.

Clinical investigation. There were only minor fluctuations of the three variables in the samples taken from the right atrium (Table I). These transiently reflected the marked changes which occurred in the blood from the limb (Figs 5 and 6). There were no cardiac arrhythmias detected on monitoring.

Neither the patients nor the experimental animals showed evidence of nerve palsies.
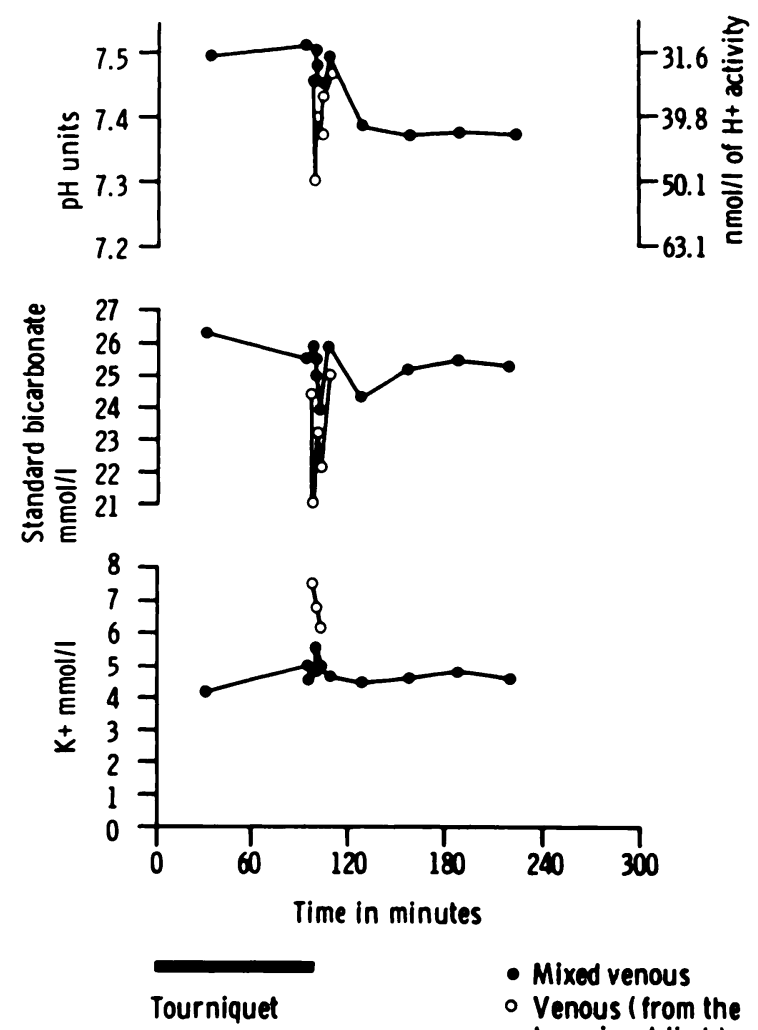

- Mixed venous

- Venous (from the tourniquet limb)

Fig. 5

Typical graphs from the patients.

Fig. 6 


\section{DISCUSSION}

In a limb that has been rendered ischaemic metabolites accumulate as a result of hypoxia in the tissues. Theoretically, a rapid influx of some of these products, for example potassium, into the coronary circulation is likely to produce cardiac dysfunction. In these studies, although the potassium levels in the blood leaving the limb were raised, at no time was a significant rise detected in the right atrium either in the animals or in the patients. The most likely explanation for this is a dilutional effect due to the larger volume of blood contained in the venous side of the circulation ( 50 per cent of the circulating blood volume is accommodated on the venous side and only 15 per cent in the arterial system). Similarly, the fall in $\mathrm{pH}$ in the venous blood leaving the acidotic limb was not reflected in the acid-base status of the blood samples from the right atrium. Here again the effect of dilution is a factor but, in addition, there is the efficient buffering capacity of the blood. A criticism of the sampling technique used could be based on the well-known streaming effect of blood from the venae cavae. This is well documented in relation to the measurement of venous oxygen in estimations of cardiac output. However, we are not aware of work showing that this effect is also applicable to other biochemical measurements. Although streaming within the atrium cannot be discounted it is unlikely to be an important factor as the results werre consistent. These findings are essentially in agreement with those described in patients having operations under tourniquet with lumbar epidural anaesthesia (Modig, Kolstad and Wigren 1978).

In the animal studies it was found that the acid-base balance in the limb returned to normal within 20 minutes of the release of a tourniquet that had been in place for one hour, and within $\mathbf{4 0}$ minutes after four hours of ischaemia. The practice of releasing the tourniquet at two hours for a period of 5 to 10 minutes to allow a "breathing period" does thus not seem appropriate (Bunnell 1964). Recovery was considerably delayed in a preliminary series of experiments where the blood pressure of the animal and the respiration were not carefully controlled.

The investigations that have been described were undertaken on healthy animals and fit patients who did not suffer from cardiovascular disease. When, as is not uncommon, the buffering capacity is reduced by anaemia, hypovolaemia, metabolic acidosis or preexisting vascular disease, there is likely to be a reduction in the normal range of safety. In addition, under certain conditions a compromised myocardium may be sensitised to catecholamines by anaesthetic agents. Under these circumstances the period during which a tourniquet is used should be reduced to the minimum and full cardiovascular monitoring must be available. The changes noted in the acid-base balance indicate that a period of three hours under a tourniquet is safe. This coincides with findings made in histological studies of the ischaemic muscle (Patterson and Klenerman 1979). Further work is in progress on muscle function.

The absence of neurological complications in the experimental animals is probably related to the use of a pressure of $\mathbf{3 0 0}$ millimetres of mercury for occlusion of the circulation. Nerve damage which occurs at the site of compression is a direct mechanical effect of the applied pressure rather than a result of ischaemia of the compressed nerve (Ochoa, Fowler and Gilliatt 1972) and a pressure of 1000 millimetres of mercury is needed to produce a block in nerve conduction in the lower limb of baboons. Similarly, in an experiment on dogs with tourniquets applied for five hours at a pressure of 600 to 650 millimetres of mercury, palsies were noted (Paletta, Willman and Ship 1960).

In conclusion it can be stated that the systemic changes produced as a result of the application of a tourniquet for periods of up to three hours are not marked and are readily reversible, provided the blood pressure and acid-base status of the subject is stable. The local acid-base changes in a limb rendered ischaemic by a tourniquet for as long as three hours recover in less than $\mathbf{4 0}$ minutes. Three hours would thus appear to be a reasonable upper time limit for the use of a tourniquet with safety.

\section{REFERENCES}

Bunnell S. Surgery of the hand. Revised by Boyes JH. 4th ed. Montreal: Pitman, 1964:132.

Déry R, Pelletier J, Jacques A, Clavet M, Houde JJ. Metabolic changes induced in the limb during tourniquet ischaemia. Can Anaesth Soc J $1965 ; 12: 367-78$.

Modig J, Kolstad K, Wigren A. Systemic reactions to tourniquet ischaemia. Acta Anaesthesiol Scand 1978;22:609-14.

Ochoa J, Fowler TJ, Gilliatt RW. Anatomical changes in peripheral nerves compressed by a pneumatic tourniquet.J Anat 1972;113:433-55.

Paletta FX, Willman V, Ship AG. Prolonged tourniquet ischemia of extremities: an experimental study on dogs. J Bone Joint Surg [Am] $1960 ; 42-A: 945-50$.

Patterson S, Klenerman L. The effect of pneumatic tourniquets on the ultrastructure of skeletal muscle. J Bone Joint Surg [Br] 1979;61-B:178-83.

Solonen KA, Tarkkanen L, Närvänen S, Gordin R. Metabolic changes in the upper limb during tourniquet ischaemia. Acta Orthop Scand 1968;39:20-32.

Stock W, Bohn HJ, Isselhard W. Metabolic changes in rat skeletal muscle after acute arterial occlusion. Vasc Surg 1971;5:249-55.5

Wilgis EFS. Observations on the effects of tourniquet ischemia. J Bone Joint Surg [Am] 1971;53-A:1343-6. 